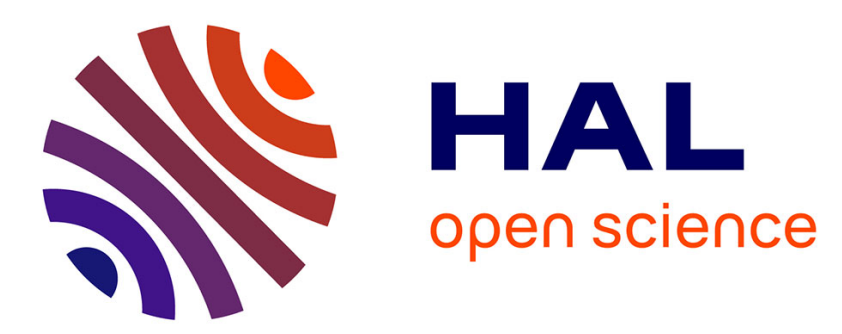

\title{
Match-mismatch effects in two-fold transfer of chirality within a Mobius metallo-receptor
}

Bernard Boitrel, Stéphane Le Gac

\section{To cite this version:}

Bernard Boitrel, Stéphane Le Gac. Match-mismatch effects in two-fold transfer of chirality within a Mobius metallo-receptor. Chemical Communications, 2020, 56 (64), pp.9166-9169. $10.1039 / \mathrm{d} 0 \mathrm{cc} 03877 \mathrm{f}$. hal-02928633

\section{HAL Id: hal-02928633 \\ https://hal.science/hal-02928633}

Submitted on 19 Nov 2020

HAL is a multi-disciplinary open access archive for the deposit and dissemination of scientific research documents, whether they are published or not. The documents may come from teaching and research institutions in France or abroad, or from public or private research centers.
L'archive ouverte pluridisciplinaire HAL, est destinée au dépôt et à la diffusion de documents scientifiques de niveau recherche, publiés ou non, émanant des établissements d'enseignement et de recherche français ou étrangers, des laboratoires publics ou privés. 


\title{
Match-Mismatch Effects in Twofold Transfer of Chirality within a Möbius Metallo-Receptor
}

Received 00th January 20xx,

\author{
Bernard Boitrel *a and Stéphane Le Gac *a
}

Accepted 00th January 20xx

DOI: 10.1039/x0xx00000x

Twofold transfer of chirality has been investigated in a Möbius $\mathrm{Zn}$ (II) hexaphyrin metallo-receptor able to bind simultaneously two different chiral molecules. Match/mismatch effects influence the dynamic stereoselective twisting of the $\pi$-system, and allow tuning the induced chiroptical activity. Such an allosteric control is attractive to build up chirality sensing systems.

Chirality inherent to Möbius topology has recently regained interest, boosted by the booming of Möbius aromaticity. ${ }^{1}$ As predicted by Heilbronner almost 60 years ago, ${ }^{2}$ cyclic $\pi$ conjugated systems featuring half-a twist follow aromaticity rules opposite to planar systems, and therefore $4 \mathrm{n}$ Möbius (hetero)annulenes exhibit variable degrees of aromaticity. ${ }^{3}$ Major advances in the design of Möbius $\pi$-systems were accomplished over the last decade with the broad family of expanded porphyrins, ${ }^{4,5}$ that present several advantages: straightforward preparation, relatively good stability, wide range of metal coordination, strong light absorption (eventually in the NIR region), two-photon absorption, and last but not least, conformational flexibility that can be controlled via different stimuli. The latter property makes these macrocycles attractive to build up Möbius adaptative systems, such as molecular receptors that can feature induced-fit or allosteric processes. ${ }^{6}$ Indeed, the strong interplay between conformation, (anti)aromaticity, and chirality may afford large and tunable chiroptical activity variation, of particular interest for sensing systems. Mastering Möbius chirality is thus crucial to control and enrich the properties of ensuing molecular systems. To do so, transfer of chirality from a chiral source to a Möbius ring, aiming at asymmetric winding of the $\pi$-system, deserves intense investigations. To the best of our knowledge, only few systems have been reported to date, all involving a [28]hexaphyrin scaffold (Figure 1). Osuka et al. reported the very first asymmetric preparation of a Möbius hexaphyrin $\mathrm{Pd}(\mathrm{II})$ complex using a chiral palladium salt, with a moderate $23 \%$ e.e. (Figure 1a). ${ }^{5 c}$ In a different approach relying on dynamic transfer of

\footnotetext{
a. Univ Rennes, CNRS, ISCR (Institut des Sciences Chimiques de Rennes)-UMR 6226, Rennes F-35000, France

b.E-mail: stephane.legac@univ-rennes1.fr, bernard.boitrel@univ-rennes1.fr. Electronic Supplementary Information (ESI) available: experimental part and NMR spectra. See DOI: 10.1039/x0xx00000x
}

chirality, ${ }^{7}$ our group has shown more efficient stereoselective controls of the Möbius twist (up to $76 \%$ d.e.), either from metalbound molecules (Figure 1b) ${ }^{6 a}$ or from covalently attached sources (Figure 1c). ${ }^{6 c}$ Pursuing our efforts, we describe herein relatively simple $\mathrm{Zn}(\mathrm{II})$ hexaphyrin complexes undergoing twofold transfer of chirality upon simultaneous binding of two chiral molecules (Figure 1d), demonstrating an efficient allosteric tuning of the resulting chiroptical activity.

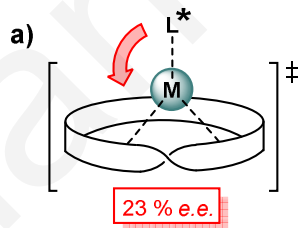

c)

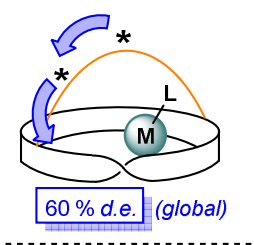

$\Longrightarrow$ Kinetic control

$\Longrightarrow$ Thermodynamic control b)

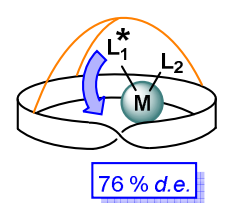

d) This work:

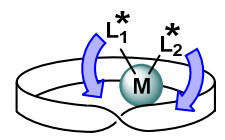

Figure 1. Transfer of chirality (red/blue arrows) in Möbius aromatic [28] hexaphyrin metal complexes: a) at the transition state of a metal insertion process $\left.[\mathrm{M}=\mathrm{Pd}(\mathrm{II})] ;^{5 \mathrm{c}} \mathrm{b}\right)$ from a metal-bound molecule in a capped-hexaphyrin metallo-receptor $[\mathrm{M}=\mathrm{Zn}(\mathrm{II})]{ }^{6 \mathrm{6a}} \mathrm{c}$ ) from two sources in covalently bridged hexaphyrin-cyclodextrin hybrids [M $=\mathrm{Zn}(\mathrm{II})] ; 6 \mathrm{c} d$ ) from two metal-bound molecules in a hexaphyrin metallo-receptor $[\mathrm{M}=\mathrm{Zn}(\mathrm{II})]$.

[28]Hexaphyrin 2 (Scheme 1), functionalized with 2acetamidophenyl and pentafluorophenyl groups in alternate meso positions, was designed aiming at simpler receptors than those bearing a tripodal cap (Figure 1b). ${ }^{\text {6a }}$ This particular mesosubstitution pattern affords electron withdrawing groups enhancing the hexaphyrin scaffold stability, and $\mathrm{H}$ bond donor moieties promoting $\mathrm{Zn}$ (II) complexation through a second sphere of coordination with amino/carboxylato ligands. ${ }^{6 a}$ Compound $\mathbf{2}$ was prepared in one step from the known [26]hexaphyrin 1 (Scheme 1). Reduction of both the nitro groups by $\mathrm{Pd}(0) / C$ catalyzed hydrogenation, and the hexaphyrin 

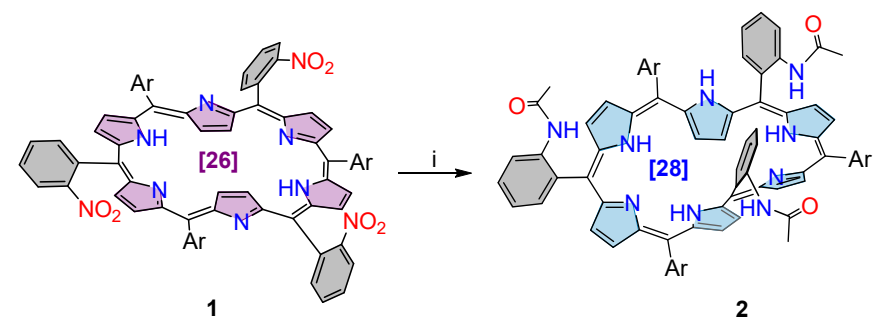

2
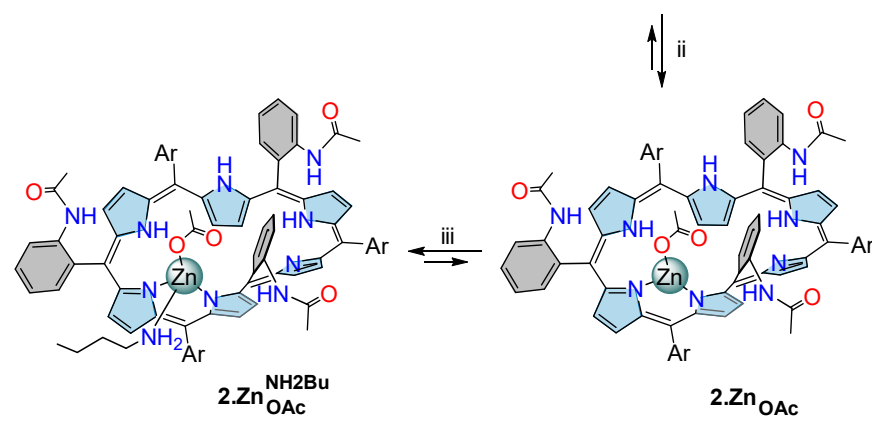

Scheme 1. Synthesis of [28] hexaphyrin $2\left(\mathrm{Ar}=\mathrm{C}_{6} \mathrm{~F}_{5}\right)$ and subsequent $\mathrm{Zn}(\mathrm{II})$ insertion in the presence of two different guest molecules (for the sake of clarity, only one possible isomer [Möbius conformation and 2-acetamidophenyl orientation] is displayed; for consistency with related previous work, ${ }^{6 a}$ a monodentate coordination of $\mathrm{OAc}$ is arbitrarily depicted): i) $\mathrm{H}_{2}$ (80 bars), $\mathrm{Pd}(0) / \mathrm{C}, \mathrm{AcOEt}, \mathrm{RT}, 15 \mathrm{~h}$; then $\mathrm{AcCl}, \mathrm{TEA}, \mathrm{THF}, 0^{\circ} \mathrm{C}$, $30 \mathrm{~min}$; ii) $\mathrm{Zn}(\mathrm{OTf})_{2}$, DIPEA, TBAOAc, $\mathrm{CDCl}_{3} / \mathrm{CD}_{3} \mathrm{OD} 9: 1$ (298 K); iii) $\mathrm{BuNH}_{2}(298 \mathrm{~K})$.

core ([26] -> [28] $\pi$-system), , ${ }^{\text {a }}$ followed by an acylation reaction of the amino moieties with acetyl chloride, led to the desired [28]hexaphyrin $\mathbf{2}$ in moderate yield upon silica gel chromatography purification (23\%). HRMS analysis indeed confirmed the reduced state of the hexaphyrin scaffold featuring a [28] $\pi$-system. 2 exhibits an intense blue colour in solution, and its UV-vis absorption spectrum is characteristic of an aromatic species, with a sharp intense Soret-like band at 606 $\mathrm{nm}$ and four Q-like bands spanning from 730 to $1060 \mathrm{~nm}$ (SI). ${ }^{8}$ Its ${ }^{1} \mathrm{H}$ NMR spectrum in $\mathrm{CDCl}_{3}$ exhibits marked broadening at $298 \mathrm{~K}$, indicating a conformationally flexible compound (SI). ${ }^{9}$
These experimental observations are consistent with a predominant aromatic Möbius conformation undergoing fluxional equilibrium (fast exchange process on the NMR time scale), as previously observed with related compounds. ${ }^{5 b, 6 a, 10}$ Atropisomerism involving the meso 2-acetamidophenyl groups likely contributes as well to this ill-resolved ${ }^{1} \mathrm{H}$ NMR spectrum. $\mathrm{Zn}(\mathrm{II})$ insertion in $\mathbf{2}$ was investigated by ${ }^{1} \mathrm{H}$ NMR experiments in 9:1 $\mathrm{CDCl}_{3} / \mathrm{CD}_{3} \mathrm{OD}$. In the presence of DIPEA, addition of $\mathrm{Zn}(\mathrm{OTf})_{2}$ led only to partial consumption of $\mathbf{2}$ affording minor unidentified species with non-trivial resonances in the highfield region (Figure $2 \mathrm{~b}$ ). In contrast, subsequent addition of TBAOAc led instantaneously to complete disappearance of $\mathbf{2}$ and to the formation of several species featuring dissymmetric patterns (Figure 2c), the two major ones (ca. 1:1 ratio) being partially characterized by 2D NMR spectra. They display three sets of $\beta$ pyrrolic protons, around $-2 \mathrm{ppm}$ (blue triangles, inner $\beta$-pyr), 4.5 ppm (green triangles, twisted $\beta$-pyr) and 7-8 ppm (red triangles, outer $\beta$-pyr). These patterns correspond to aromatic Möbius conformations, rigidified on the NMR time scale by $\mathrm{Zn}(\mathrm{II})$ complexation, with a typical diatropic ring current shielding the inside and deshielding the outside of the hexaphyrin core. ${ }^{5 b, 6 a}$ 2D ROESY NMR experiment indicates that shielded signals at -1 ppm correspond to acetate molecules oriented inward (Figure 2c, blue dot, $\Delta \delta=-2.9 \mathrm{ppm}$ ), in agreement with the binding of a 'ZnOAc' moiety at a dipyrrin site (Scheme 1, 2.ZnoAc), as in related tren-capped hexaphyrin complexes. ${ }^{6 a, 11}$ The 2acetamidophenyl group adjacent to the twisted pyrrole (bound to zinc) is projected towards the hexaphyrin core and thus experiences partial shielding (Figure 2c, orange dots). This feature likely reinforces the dissymmetry at the level of the metal centre. More detailed NMR characterization is hampered by the complexity of the spectrum. ${ }^{12}$

Subsequent addition of $\mathrm{BuNH}_{2}$ led to a new set of NMR patterns with at least the three major species retaining the characteristic resonances of $\mathrm{Zn}$ (II) Möbius complexes with a 2acetamidophenyl group projected towards the hexaphyrin
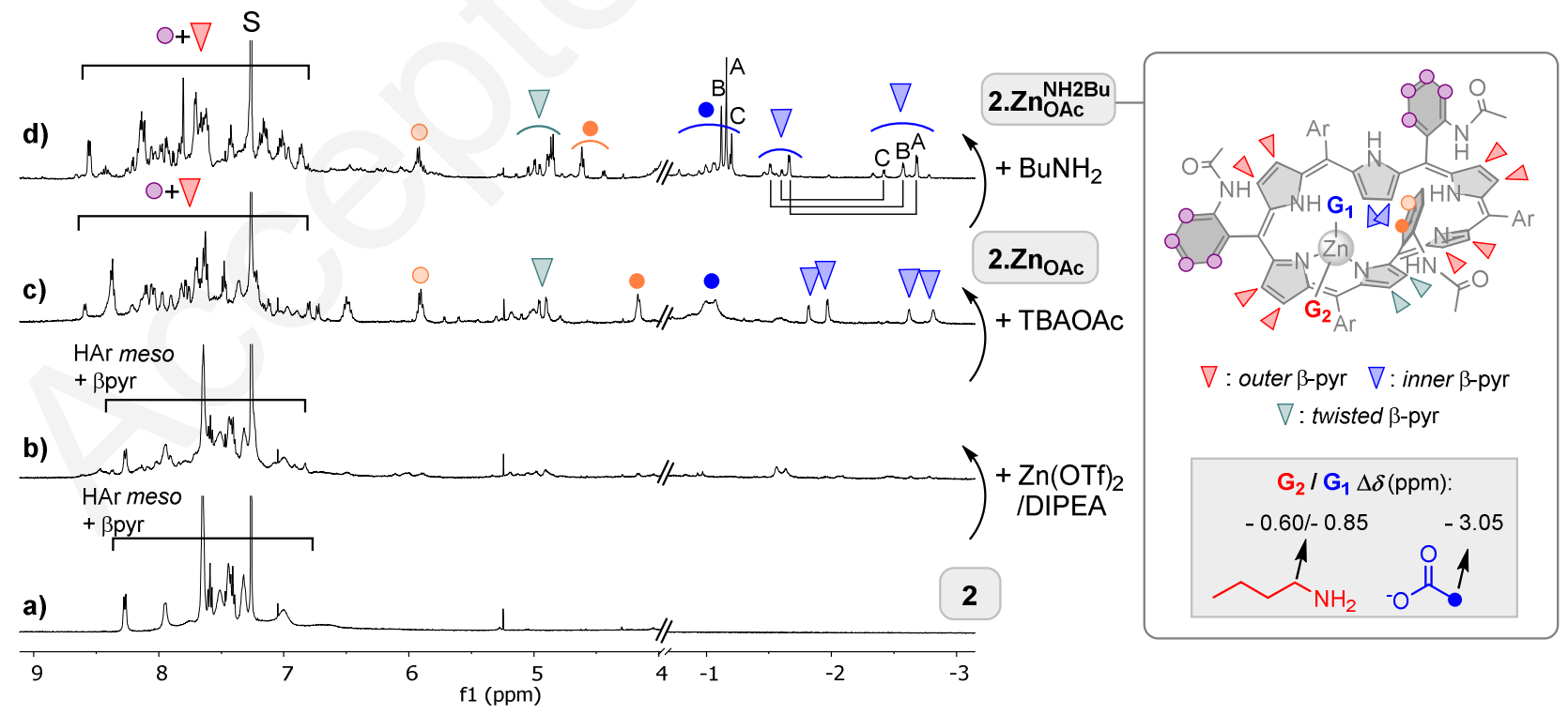
Figure 2. ${ }^{1} \mathrm{H}$ NMR study of the metallation of 2 with $\mathrm{Zn}(\mathrm{II})\left(\mathrm{CDCl}_{3} / \mathrm{CD}_{3} \mathrm{OD} 9: 1,298 \mathrm{~K}, 500 \mathrm{MHz}\right)$ : a) 2 at $4.4 \mathrm{mM}$; b) upon addition of $1.5 \mathrm{equiv}$. of $\mathrm{Zn}(\mathrm{OTf})_{2}$ and 5 equiv. of DIPEA; $\left.\mathrm{C}\right)$ upon addition of 3 equiv. of TBAOAc; d) upon addition of 5 equiv. of $\mathrm{BuNH}_{2}$ (at $278 \mathrm{~K}$; signals labelled " $\mathrm{A}$ ", " $\mathrm{B}$ " and " $\mathrm{C}$ " belong to the three major species). $\mathrm{S}=$ solvent. Inset : $\Delta \delta=$ $\delta_{\text {bound }} \delta_{\text {tree. }}$.

core (Figure 2d, labelled " $\mathrm{A}$ ", " $\mathrm{B}$ " and " $\mathrm{C}$ ") ${ }^{13}$ In addition to a $\mathrm{Zn}(\mathrm{II})$ acetato ligand oriented inward $(\Delta \delta \sim-3 \mathrm{ppm}$, Figure 2 inset), 2D ROESY NMR experiment (SI) evidences concomitant binding of a butylamino ligand, oriented outward. Indeed, only the protons in $\alpha$ position of the coordinated nitrogen atom undergo slight shielding ( $\Delta \delta \sim-0.7 \mathrm{ppm}$, Figure 2 inset), consistently with an aliphatic chain pointing away from the inner core of the Möbius hexaphyrin (Scheme 1, 2.Zn ${ }_{\text {OAc }}{ }^{\mathrm{NH2Bu}}$ ). These observations are in agreement with related tren-capped hexaphyrin complexes, in which a 4-coordinate $\mathrm{Zn}$ (II) (tetrahedral geometry) orients carboxylato and amino ligands respectively inward and outward. ${ }^{6 a}$

During the course of our investigations towards twofold transfer of chirality to the Möbius twisted $\pi$-system, we collected interesting results with two other ligands, N-Boc protected (S)-Proline (BocProOH) as inward guest and $(R / S)$ methylbenzylamine (MBA) as outward guest. With their resulting complexes, ${ }^{1} \mathrm{H}$ NMR spectroscopy does not provide direct access to chirality induction (d.e. values) due to too complex sets of NMR patterns arising from atropisomerism. In contrast, electronic circular dichroism (ECD) spectroscopy is a straightforward and efficient method to evaluate and compare $P / M$ twist stereoselectivity, since atropisomers of the same $P$ $(/ M)$ configuration will simply sum up their CD spectra. To assess twofold transfer of chirality, five situations were thus compared by both ${ }^{1} \mathrm{H}$ NMR and ECD spectroscopies (Figure 3ae), all generated from the same mixture of 2 , DIPEA and $\mathrm{Zn}(\mathrm{OTf})_{2}$ $\left(\mathrm{CDCl}_{3} / \mathrm{CD}_{3} \mathrm{OD}\right.$ 9:1, $\left.298 \mathrm{~K}\right)$ :
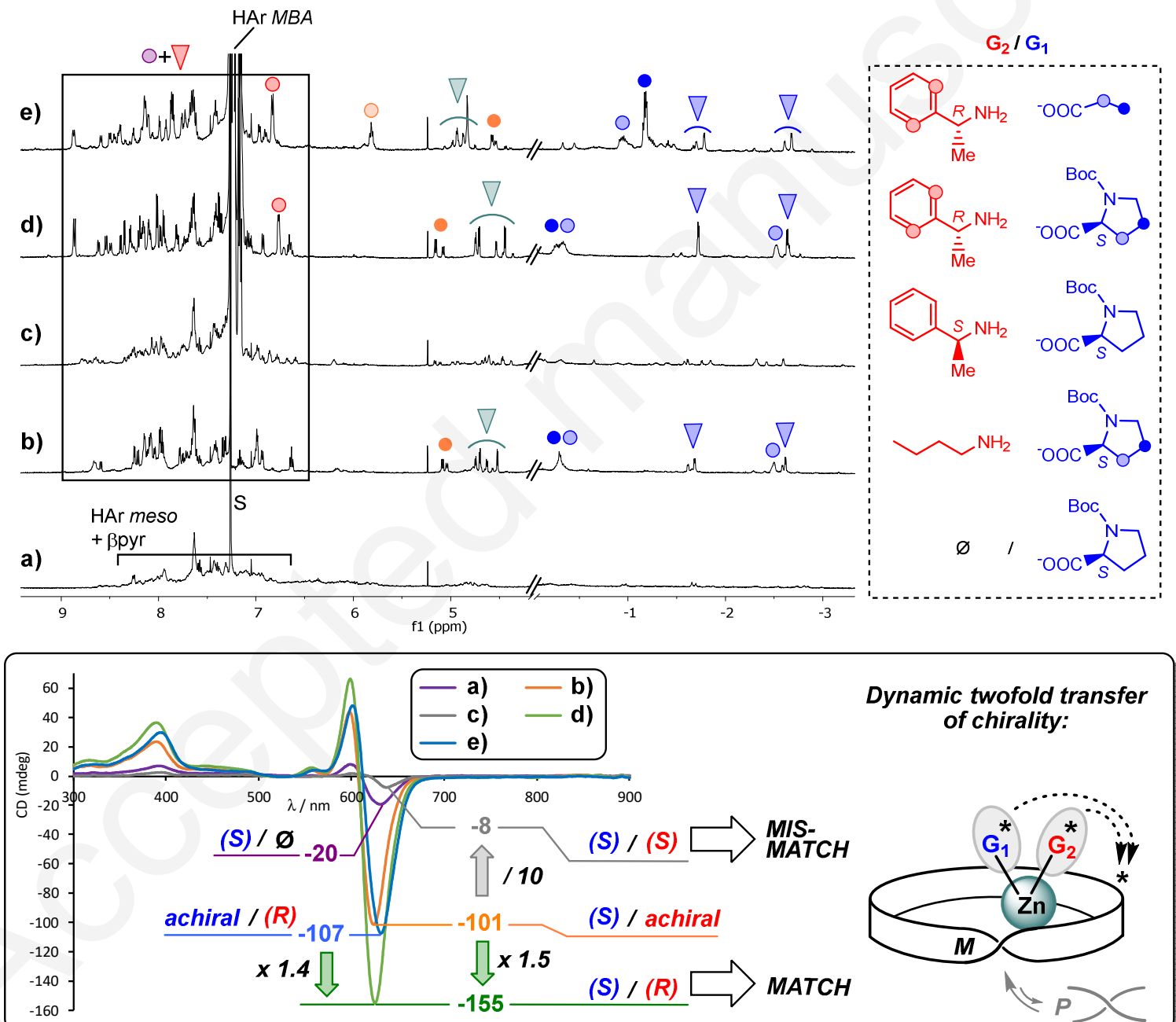

Dynamic twofold transfer of chirality:

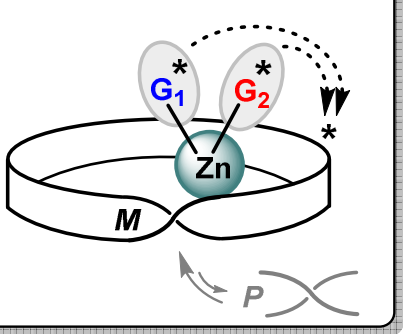

Figure 3. Assessment of the $P / M$ stereoselective formation of Möbius isomers, from ${ }^{1} \mathrm{H} N M R$ (top) and ECD (down) studies. Metallation of 2 with $\mathrm{Zn}(\mathrm{OTf})_{2} / \mathrm{DIPEA}\left(\mathrm{CDCl} / \mathrm{CD}_{3} \mathrm{OD} 9: 1\right.$, $298 \mathrm{~K}, 500 \mathrm{MHz}$ ) performed in the presence of different guest molecules: a) (S)-BocProO; b) BuNH ${ }_{2}$ and (S)-BocProO; c) (S)-MBA and (S)-BocProO; d) (R)-MBA and (S)-BocProO; e) $(R)-\mathrm{MBA}$ and $\mathrm{EtCO}_{2} \cdot \mathrm{S}=$ solvent. Proton labelling: same as Figure 2. NMR initial concentration of 2: $4.4 \mathrm{mM} ; \mathrm{ECD}$ total concentration of 2: $44 \mu \mathrm{M}(\Delta \varepsilon$ values and proportions of each species are not accessible).

(i) Whereas addition of (S)-BocProOH led to an ill-defined NMR spectrum and an ECD one of weak intensity (Figure 3a), subsequent introduction of $\mathrm{BuNH}_{2}$ led to the expected mixture of $\mathrm{Zn}$ (II) Möbius complexes with (S)-BocProO- inward and $\mathrm{BuNH}_{2}$ outward (Figure 3b; $\Delta \delta$ values in the SI). ${ }^{14,15} \mathrm{An}$ important 5-fold increase of the ECD intensity $(\lambda=624 \mathrm{~nm})$, displaying negative 
cotton effect, indicates marked chirality transfer favouring a $M$ twist. ${ }^{16}$ Such a behaviour corresponds to a cooperative process, requiring concomitant binding of the two guests;

(ii) Addition of $\mathrm{EtCO}_{2} \mathrm{H}$ and $(R)-\mathrm{MBA}$ led to a similar result, i.e. $\mathrm{Zn}$ (II)-bound carboxylato and amino ligands are respectively oriented inward and outward and support transfer of chirality favouring a $M$ twist (Figure $3 \mathrm{e}$, same $C D$ spectrum as Figure $3 \mathrm{~b}$ ). Thus, chirality transfer can proceed from inward [(S)-BocProO-] or outward $[(R)-\mathrm{MBA}]$ guests with comparable efficiency, provided that their complementary (achiral) guest is present (respectively $\mathrm{BuNH}_{2}$ and $\mathrm{EtCO}_{2}^{-}$);

(iii) Addition of $(S)$-BocProOH and (S)-MBA, that respectively favour $M$ and $P$ twists, led to an ill-defined ${ }^{1} \mathrm{H}$ NMR spectrum ${ }^{17}$ and to an ECD spectrum of weak intensity (Figure 3c; 10-fold decrease vs Figure $3 \mathrm{~b}$ ). In contrast, addition of (S)-BocProOH and $(R)-\mathrm{MBA}$, that both favour a $M$ twist, led to a very well defined ${ }^{1} \mathrm{H}$ NMR spectrum (two predominant Möbius $\mathrm{Zn}$ (II) complexes in ca. 2:1 ratio, Figure $3 \mathrm{~d}$ ), and to an ECD spectrum of higher intensity than those of the two separated chiral ligands (Figure $3 d, 50 \%$ increase vs Figure $3 b$ and $3 e$ ). Hence, an inward guest favouring a $M$ twist exhibits a mismatch effect with an outward guest favouring a $P$ twist, leading to weak recognition and poor diastereoselectivity, but exhibits a match effect with an outward guest also favouring a $M$ twist, leading to a remarkable increase of the diastereoselectivity. The same trend is observed when comparing $(R)-\mathrm{MBA}$ and $(S)$ - $\mathrm{BocProOH}$ vs $\mathrm{EtCO}_{2} \mathrm{H}$ (Figure 3d vs 3e, match effect).

These match-mismatch effects evidence an overall communication between the two sources of chirality, meaning that chirality transfers do not take precedence over one another. This feature nicely allows up or down regulation of the chiroptical activity of the Möbius $\pi$-system owing to allosterism, relying on the configuration of the two guests. This phenomenon, to date restricted to Möbius porphyrinoids, is possible because of the conformational equilibrium between the two Möbius enantiomers, allowing (twofold) transfer of chirality under thermodynamic control. Such dynamic metalloreceptors featuring highly responsive chiroptical activity are attractive to build up chirality sensing systems.

\section{Conflicts of interest}

There are no conflicts to declare.

\section{Notes and references}

1 For reviews, see: (a) H. S. Rzepa, Chem. Rev., 2005, 105, 3697-3715; (b) R. Herges, Chem. Rev., 2006, 106, 4820-4842.

2 E. Heilbronner, Tetrahedron Lett., 1964, 5, 1923-1928.

3 D. Ajami, O. Oeckler, A. Simon and R. Herges, Nature, 2003, 426, 819-821.

4 For recent reviews, see: (a) T. Tanaka and A. Osuka, Chem. Rev., 2017, 117, 2584-2640; (b) Y. Mo Sung, J. Oh, W.-Y. Cha, W. Kim, J. Min Lim, M.-C. Yoon and D. Kim, Chem. Rev., 2017, 117, 2257-2312; (c) B. Szyszko, M. J. Białek, E. PacholskaDudziak and L. Latos-Grażyński, Chem. Rev., 2017, 117, 28392909.
5 Selected leading references for Möbius hexaphyrins: (a) M. Stępień, L. Latos-Grażyński, N. Sprutta, P. Chwalisz and L. Szterenberg, Angew. Chem. Int. Ed., 2007, 46, 7869-7873; (b) J. Sankar, S. Mori, S. Saito, H. Rath, M. Suzuki, Y. Inokuma, H. Shinokubo, K. S. Kim, Z. S. Yoon, J.-Y. Shin, J. M. Lim, Y. Matsuzaki, O. Matsushita, A. Muranaka, N. Kobayashi, D. Kim and A. Osuka, J. Am. Chem. Soc., 2008, 130, 13568-13579; (c) T. Tanaka, T. Sugita, S. Tokuji, S. Saito and A. Osuka, Angew. Chem., Int. Ed., 2010, 49, 6619-6621.

6 (a) H. Ruffin, G. Nyame Mendendy Boussambe, T. Roisnel, V. Dorcet, B. Boitrel and S. Le Gac, J. Am. Chem. Soc., 2017, 139, 13847-13857; (b) S. Le Gac, E. Caytan, V. Dorcet and B. Boitrel, Org. Biomol. Chem., 2019, 17, 3718-3722; (c) R. Benchouaia, N. Cissé, B. Boitrel, M. Sollogoub, S. Le Gac and M. Ménand, J. Am. Chem. Soc., 2019, 141, 11583-11593.

7 (a) J. Clayden, Chem. Soc. Rev., 2009, 38, 817-829. (b) S. F. Pizzolato, P. Štacko, J. C. M. Kistemaker, T. van Leeuwen, E. Otten and B. L. Feringa, J. Am. Chem. Soc., 2018, 140, 1727817289. (c) M. Liu, L. Zhang and T. Wang, Chem. Rev., 2015, 115, 7304-7397.

8 S. Cho, Z. S. Yoon, K. S. Kim, M.-C. Yoon, D.-G. Cho, J. L. Sessler and D. Kim, J. Phys. Chem. Lett., 2010, 1, 895-900.

9 Low temperature ${ }^{1} \mathrm{H}$ and ${ }^{19} \mathrm{~F}$ NMR spectra (down to $190 \mathrm{~K}$ ) did not afford a single sharp signature, but rather multiple patterns with shielded signals, consistently with a mixture of Möbius aromatic conformations frozen on the NMR time scale, see the SI.

10 An energy barrier of ca. $9 \mathrm{kcal} / \mathrm{mol}$ was calculated for the benchmark meso-hexakis(pentafluorophenyl)[28] hexaphyrin, see: K. S. Kim, Z. S. Yoon, A. B. Ricks, J.-Y. Shin, S. Mori, J. Sankar, S. Saito, Y. M. Jung, M. R. Wasielewski, A. Osuka and D. Kim, J. Phys. Chem. A, 2009, 113, 4498-4506.

11 An alternative outward coordination of $\mathrm{AcO}^{-}$was not detected by 2D ROESY NMR in the present conditions (see the $\mathrm{SI}$ ), although it cannot be ruled out for minor species lacking 2D NMR correlations.

12 The UV-vis-NIR absorption spectrum of $2.2 n_{O A c}$ is characteristic of a Möbius aromatic [28] hexaphyrin, the Soretlike band being red shifted compared to 2 , see the SI.

13 Roughly, the same ratio of $A, B$ and $C(4: 2.5: 1)$ is measured from different signals (inner and twisted $\beta$-pyrrolic protons, $\mathrm{CH}_{3}$ protons of the acetato ligands, aromatic protons of the meso 2-acetamidophenyl substituent oriented inward).

14 Note that an incomplete metalation is observed in the present conditions, which is likely due the steric hindrance of BocProO- larger than that of $\mathrm{AcO}^{-}$.

15 The inward orientation of (S)-BocProO- is deduced from (i) important $\Delta \delta$ values (up to $-4.37 \mathrm{ppm}$ ) and (ii) NOE correlations with the inward oriented meso 2acetamidophenyl group adjacent to the twisted pyrrole bound to zinc (see the SI). Two predominant Möbius complexes are present in ca. 1.5:1 ratio.

16 For a definition of $M$ and $P$ stereodescriptor, see ref $6 c$. 17 More investigations are needed to analyze this mixture. 